\title{
Post-Golgi trafficking of dusanka deretic rhodopsin in retinal photoreceptors
}

\begin{abstract}
Rod outer segment renewal in retinal rod photoreceptors is mediated by polarised sorting of rhodopsin, and its associated proteins and lipids, on post-Golgi vesicles that bud from the trans-Golgi network and fuse with the specialised domain of the plasma membrane in the rod inner segment. This domain surrounds the cilium that connects the inner segment and the rod outer segment to which mature rhodopsin is delivered. The intracellular sorting machinery that regulates budding, targeting and fusion of rhodopsin carrier vesicles has been studied using multiple means including a newly developed cell-free assay that reconstitutes vesicle budding. These studies have revealed an essential role for small GTP-binding protein rab6, as well as the carboxyl-terminal domain of rhodopsin, in the formation of post-Golgi vesicles. In this report their role in post-Golgi trafficking of rhodopsin and the maintenance of photoreceptor cell polarity and health is discussed.
\end{abstract}

Key words Rhodopsin, Photoreceptors, Retina, rab proteins, GTP-binding proteins, post-Golgi trafficking

Rhodopsin and the associated proteins that participate in visual transduction are housed in a unique subcellular domain of retinal photoreceptor cells, the rod outer segment (ROS). ${ }^{1}$ Rod outer segments are filled with numerous flattened membranous discs that have unique protein and lipid composition. Rhodopsin represents approximately $90 \%$ of the membrane protein of the discs, ${ }^{2,3}$ where it is embedded in a highly fluid lipid milieu that facilitates its lateral diffusion upon light activation. ${ }^{4,5}$ Components of the ROS disc membranes are continuously renewed throughout life. ${ }^{6}$ Proteins and lipids necessary for the disc membrane assembly are synthesised in the rod inner segments ${ }^{7,8}$ and delivered to the ROS in a polarised fashion. The maintenance of healthy photoreceptors entails sorting of rhodopsin and its associated proteins and lipids into specialised post-Golgi vesicles that bud from the trans-Golgi network (TGN) and fuse with the plasma membrane near the cilium that connects inner and outer segments. ${ }^{9-11}$ Gaining insight into the processes that underlie formation of these vesicles, their polarised transport and subsequent fusion with the plasma membrane will afford better understanding of intracellular mechanisms that govern polarised membrane renewal. This in turn will help to elucidate aberrant membrane transport caused by mutations in photoreceptor proteins that lead to retinal degeneration and blindness.

\section{Rhodopsin-bearing post-Golgi vesicles}

Post-Golgi vesicles carrying newly synthesised rhodopsin were first observed by immunoelectron microscopy and autoradiography in amphibian retinas. ${ }^{11,12}$ Because of the high membrane turnover, at a rate of up to $3 \mu \mathrm{m}^{2} / \mathrm{min}^{13}$ the post-Golgi compartment in amphibian retinas is large and well defined. Post-Golgi vesicles carrying rhodopsin were isolated from frog retinas and characterised..$^{10}$ As a consequence of their unique low buoyant density in sucrose gradients and the kinetics of their labelling by pulse-chase experiments, they were readily separated from other subcellular compartments. ${ }^{10}$ The protein composition of rhodopsin-bearing vesicles is relatively simple. In addition to rhodopsin they also contain transducin and cGMP phosphodiesterase. ${ }^{10}$ Several low-molecular-weight GTP-binding proteins of the rab family, namely rab3, rab6, rab8 and rab11, are tightly associated with vesicle membranes., ${ }^{9,14,15}$ These proteins may be important regulators of rhodopsin transport since rab proteins are known regulators of intracellular trafficking. ${ }^{16}$ In addition, $\alpha \mathrm{A}-$ and $\alpha \mathrm{B}$-crystallin were also found bound to vesicle membranes; their function in this step of rhodopsin trafficking is not understood at present. ${ }^{17}$ Finally, phospholipids containing docosahexaenoic acid (DHA), a polyunsaturated fatty acid that is highly enriched in the ROS disc membranes, ${ }^{18,19}$ and 
phosphatidylcholine and phosphatidylethanolamine components of these membranes in particular, are also incorporated in the same vesicles as rhodopsin as they bud from the TGN. ${ }^{20}$ These data suggest that a significant enrichment of ROS proteins and lipids occurs in the process of post-Golgi vesicle budding.

\section{A cell-free system that reconstitutes formation of post- Golgi vesicles}

Studies of rhodopsin trafficking in living cells are hindered by the structure and organisation of the retina. Inner segments of photoreceptor cells are surrounded by the neural retina on one side and the ROS layer encased in interphotoreceptor matrix on the other. This prevents easy access to the inner segments that would allow cell permeabilisation and introduction of antibodies, peptides and other membrane-impermeable agents to photoreceptor cells and perturbation of intracellular trafficking. To circumvent this problem a retinal cell-free system has been developed that reconstitutes formation of rhodopsin-bearing post-Golgi vesicles in vitro. ${ }^{9}$

In this cell-free assay frog retinas are isolated and radiolabelled for $1 \mathrm{~h}$ in retinal cultures, at which point newly synthesised proteins are predominantly found in the Golgi complex. ${ }^{10}$ At that time ROS are removed and photoreceptor organelles involved in the biosynthesis of the ROS proteins are released from the remainder of the retina by low-shear homogenisation. Biosynthetic membranes are recovered in the post-nuclear supernatant after low-speed centrifugation. Post-nuclear supernatants are then incubated for $2 \mathrm{~h}$ of cell-free chase in the presence of ATP and an ATP-regenerating system or in the presence of an ATP-depleting system. In the presence of ATP and cytosol post-Golgi vesicles bud from the TGN. These vesicles are indistinguishable from the vesicles formed in vivo by the criteria of their buoyant density, protein composition, topology and morphology. ${ }^{9}$ Simultaneously with vesicle budding, resident proteins are retained in the TGN. Therefore, rhodopsin and its associated proteins are sorted upon exit from the TGN in this cell-free system.

Establishment of the cell-free system is a milestone in providing access to photoreceptor biosynthetic membranes at the critical step when newly synthesised proteins and lipids are incorporated into rhodopsinbearing vesicles. Reconstitution of intracellular trafficking in cell-free systems derived from various cell types has identified new families of membrane receptors, termed SNAREs, and their associated proteins, including rab proteins, that are highly conserved among species and regulate vesicle budding, docking and fusion events in organisms as diverse as yeast and humans. ${ }^{21-23}$ Photoreceptor cells with their complex polarised organisation and a well-studied major protein, rhodopsin, are ideally suited to extend these studies to better understand both common mechanisms of intracellular sorting and the unique role of rhodopsin in these events, since numerous natural disease-causing mutations have helped to identify domains of rhodopsin that potentially determine its intracellular fate.

\section{Rab proteins regulate post-Golgi trafficking of rhodopsin}

With this powerful new tool in hand, addressing the role of regulatory proteins in rhodopsin trafficking became possible. To study the role of rab proteins in these processes rab proteins have been extracted from the membranes, prior to cell-free vesicle formation, by the addition of rab GDP dissociation inhibitor (GDI). Rab GDI is a rab-accessory protein that forms a complex with a rab protein in its inactive, GDP-bound form in the cytosol and prevents dissociation of GDP and nonspecific activation by high intracellular concentrations of GTP. ${ }^{24}$ This complex dissociates when it encounters a specific nucleotide exchange factor on the membrane that catalyses GDP/GTP exchange and activates rab protein. ${ }^{25}$ Addition of excess of rab GDI causes retinal rab proteins to dissociate from membranes. This completely inhibits post-Golgi vesicle formation and arrests newly synthesised rhodopsin in the Golgi. ${ }^{9}$

One of the rab proteins that resides predominantly in the Golgi, the TGN and on post-Golgi vesicles is rab6. This protein is also removed from the membranes by the action of rab GDI and is a likely candidate to regulate the step in rhodopsin trafficking that is affected by rab GDI. To test the role of rab6 in vesicle formation, we have synthesised peptides that correspond to the 'effector domain' of rab6 and, as a control, rab7. Based on the high homology with $221^{\text {ras }}$ protein, ${ }^{26}$ whose crystal structure has been solved, ${ }^{27}$ a model of rab6 was generated and the amino acids that form the 'effector loop' identified. The effector domain of p $21^{\text {ras }}$ is centred around a highly conserved threonine, Thr 35. It is involved in the nucleotide-dependent conformational change that modulates its interactions with effectors. ${ }^{28}$ The effector domains of rab proteins and their yeast counterparts define their functional specificity, as has been shown by examination of chimeric small G-proteins. ${ }^{29-31}$ The effector domain of rab6 is also essential for its interaction with rab GDI. ${ }^{32}$ The effector domain of rab7 was chosen as a control because rab7 regulates late endocytic membrane traffic in other cells ${ }^{33}$ and was shown to be absent from rhodopsin-bearing membranes in photoreceptors. ${ }^{34}$

The rab6 effector peptide (AA 37-52) completely inhibited vesicle formation and arrested newly synthesised rhodopsin in the Golgi in a manner similar to rab GDI (D. Deretic, B. Puleo-Scheppke and C. Trippe, manuscript in preparation). The peptide derived from rab7 (AA 33-47) had no effect on rhodopsin trafficking. It appears that in the presence of the rab6 effector peptide Golgi membranes fuse with the endoplasmic reticulum (ER). This suggests that rab6 is critical for the maintenance of photoreceptor Golgi and possibly for the TGN and post-Golgi vesicles as well. Similar observations were made in HeLa cells overexpressing a 
A

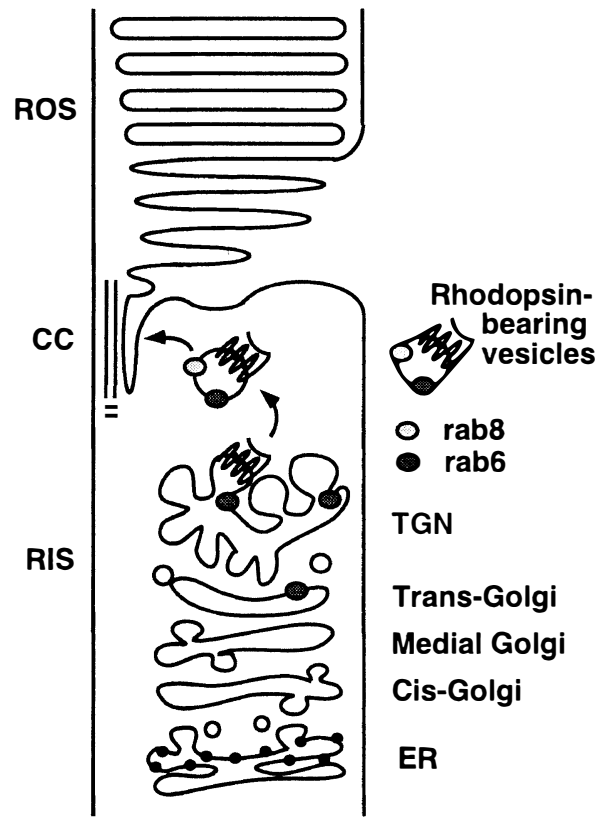

B

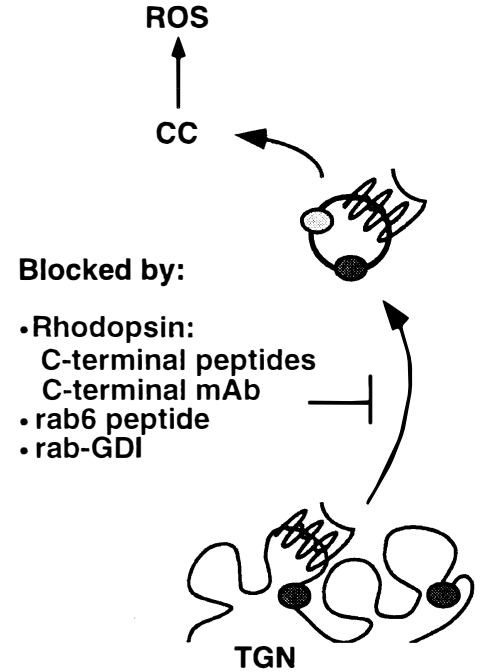

Fig. 1. (A) Schematic diagram of rhodopsin trafficking in retinal photoreceptors. Following synthesis on the membranes of the endoplasmic reticulum (ER) and oligosacharide processing in the Golgi, newly synthesised rhodopsin is incorporated into post-Golgi vesicles that bud from the trans-Golgi network (TGN). Post-Golgi vesicles fuse with the plasma membrane of the rod inner segment (RIS) near the connecting cilium (CC) prior to the delivery of rhodopsin to the rod outer segment (ROS). Subcellular distribution of small GTP-binding proteins rab6 and rab8 suggests that they regulate successive steps in post-Golgi trafficking of rhodopsin. ${ }^{14,15,34}$ (B) Rab proteins and the C-terminal domain of rhodopsin are important regulators of post-Golgi trafficking of rhodopsin. Post-Golgi vesicle formation is inhibited by rab GDP dissociation inhibitor (rab GDI) ${ }^{9}$ and by the peptide that corresponds to the 'effector domain' of rab6 (manuscript in preparation). Monoclonal antibody to the C-terminal of rhodopsin inhibits vesicle formation ${ }^{9}$ and so do peptides that contain the last five amino acids of rhodopsin, QVS(A)PA (D. Deretic, P. Hargrave, $H$. McDowell and A. Arendt, submitted).

mutant, GTP-bound form of rab6 protein that also caused Golgi-ER fusion. ${ }^{35}$ It is not clear whether rab6 in photoreceptors performs another function in addition to regulating traffic through the Golgi, since approximately $10 \%$ of total rab6 is associated with post-Golgi vesicles. This will be a subject for future investigation.

\section{The carboxyl-terminal of rhodopsin regulates post-} Golgi vesicle formation

A very important clue to the possible role of the carboxyl-terminal (C-terminal) domain of rhodopsin in its intracellular trafficking came from the observation that the monoclonal antibody whose antigenic site is within nine amino acids of the C-terminal inhibits postGolgi vesicle formation and arrests rhodopsin in the TGN. ${ }^{9}$ Fab fragments from this antibody have the same effect, indicating that the inhibition is not due to membrane cross-linking. ${ }^{9}$ To further examine the role of the C-terminal domain in post-Golgi trafficking we synthesised several peptides corresponding to this and other domains from frog and mammalian rhodopsin, and tested the effect of these peptides on retinal cell-free vesicle formation. Peptides homologous to the last 24 amino acids of frog and bovine rhodopsin inhibited vesicle formation and arrested newly synthesised rhodopsin in the TGN, similar to the inhibitory C-terminal antibody (D. Deretic, P. Hargrave, $\mathrm{H}$. McDowell and A. Arendt, submitted). Truncation of five amino acids from the amino(N)-terminal of these peptides had no effect on their capability to inhibit rhodopsin transport. However, truncation of the last five amino acids completely abolished the inhibitory effect of both frog and bovine peptides.

The five C-terminal amino acids of rhodopsin QVS(A)PA are highly conserved among species. ${ }^{1}$ Several mutations that cause severe forms of the human disease autosomal dominant retinitis pigmentosa (ADRP) cluster in the C-terminal region of the protein. ${ }^{36-38}$ These mutations have been modelled in transgenic animals and it was found that they cause mislocalisation of the mutant rhodopsin. ${ }^{39,40}$ Our data explain the step in intracellular trafficking at which the C-terminal domain plays a critical role. This occurs as rhodopsin in the TGN membranes binds to the regulatory protein(s) that recognise the last five amino acids, which we can, therefore, call the sorting signal. Lack of recognition of this sequence by interference with the synthetic peptides, or by mutations affecting the structure of this domain, may cause missorting or prolong the transit time of rhodopsin through the Golgi, which could result in its aberrant subcellular localisation. 


\section{Conclusions}

In conclusion, a new approach introduced to the studies of subcellular trafficking of rhodopsin is yielding valuable information about molecular mechanisms that underlie rhodopsin sorting to the ROS. Further studies of the rab proteins and their regulators will help to distinguish between the photoreceptor-specific and common regulatory pathways in intracellular trafficking. What is even more promising is that understanding of the interactions of the C-terminal of rhodopsin with intracellular sorting machinery will help explain the critical steps affected by mutations in the C-terminal domain of rhodopsin in patients with ADRP. When interacting proteins are identified they may be targeted by potential treatments to alleviate the problems caused by the lack of interaction with mutant rhodopsin.

I thank Dr David Papermaster for thoughtful discussions and advice, and Belen Puleo-Scheppke, Claudia Trippe and Nancy Ransom for their invaluable help throughout the course of this work. I also thank Dr Bruno Goud for his generous gift of antibodies and rab GDI, and Drs Paul Hargrave, Hugh McDowell and Anatol Arendt for their participation in studies of peptide inhibition of transport.

\section{References}

1. Hargrave PA, McDowell JH. Rhodopsin and phototransduction. Int Rev Cytol 1992;137b:49-97.

2. Papermaster DS, Dreyer WJ. Rhodopsin content in the outer segment membranes of bovine and frog retinal rods. Biochemistry 1974;13:2438-44.

3. Basinger S, Bok D, Hall M. Rhodopsin in the rod outer segment plasma membrane. J Cell Biol 1976;69:29-42.

4. Liebman PA, Entine G. Lateral diffusion of visual pigment in photoreceptor disc membranes. Science 1974;185:457-9.

5. Poo M, Cone RA. Lateral diffusion of rhodopsin in the photoreceptor membrane. Nature 1974;247:438-41.

6. Young RW. Visual cells and the concept of renewal. Invest Ophthalmol Vis Sci 1976;15:700-25.

7. Hall MO, Bok D, Bacharach AD. Biosynthesis and assembly of the rod outer segment membrane system: formation and fate of visual pigment in the frog retina. J Mol Biol 1969;45:397-406.

8. Mercurio AM, Holtzman E. Ultrastructural localization of glycerolipid synthesis in rod cells of the isolated frog retina. J Neurocytol 1982;11:295-322.

9. Deretic D, Puleo-Scheppke B, Trippe C. Cytoplasmic domain of rhodopsin is essential for post-Golgi vesicle formation in a retinal cell-free system. J Biol Chem 1996;271:2279-86.

10. Deretic D, Papermaster DS. Polarized sorting of rhodopsin on post-Golgi membranes in frog retinal photoreceptor cells. J Cell Biol 1991;113:1281--93.

11. Papermaster DS, Schneider BG, Besharse JC. Vesicular transport of newly synthesized opsin from the Golgi apparatus toward the rod outer segment: ultrastructural immunocytochemical and autoradiographic evidence in Xenopus retinas. Invest Ophthalmol Vis Sci 1985;26:1386-404

12. Papermaster DS, Schneider BG, Defoe D, Besharse JC. Biosynthesis and vectorial transport of opsin on vesicles in retinal rod photoreceptors. J Histochem Cytochem 1986;34:5-16.

13. Besharse JC. Photosensitive membrane turnover: differentiated membrane domains and cell-cell interaction. In: Adler R, Farber D, editors. The retina: a model for cell biological studies. New York: Academic Iress, 1986:297-352.
14. Deretic D, Papermaster DS. Rab6 is associated with a compartment that transports rhodopsin from the trans-Golgi to the site of rod outer segment disc formation in frog retinal photoreceptors. J Cell Sci 1993;106:803-13.

15. Deretic D, Huber LA, Ransom N, Mancini M, Simons K, Papermaster DS. rab8 in retinal photoreceptors may participate in rhodopsin transport and in rod outer segment disc morphogenesis. J Cell Sci 1995;108:215-24.

16. Pfeffer SR. Rab GTPases: master regulators of membrane trafficking. Curr Opin Cell Biol 1994;6:522-6.

17. Deretic D, Aebersold RH, Morrison HD, Papermaster DS Alpha-A- and alpha B-crystallin in the retina: association with the post-Golgi compartment of frog retinal photoreceptors. J Biol Chem 1994;269:16853-61.

18. Aveldano MI, Bazan NG. Molecular species of phosphatidylcholine, -ethanolamine, -serine, and -inositol in microsomal and photoreceptor membranes of bovine retina. J Lipid Res 1983;24:620-7.

19. Fliesler SJ, Anderson RE. Chemistry and metabolism of lipids in the vertebrate retina. I'rog Lipid Res 1983;22:79-131.

20. Rodriguez de Turco EB, Deretic D, Bazan NG, Papermaster DS. Post-Golgi vesicles cotransport docosahexaenoylphospholipids and rhodopsin during frog photoreceptor membrane biogenesis. J Biol Chem 1997;272:10491-7.

21. Schekman R, Orci L. Coat proteins and vesicle budding. Science 1996;271:1526-33.

22. Sollner TH, Rothman JE. Molecular machinery mediating vesicle budding, docking and fusion. Cell Struct Funct 1996;21:407-12.

23. Pfeffer SR. Transport vesicle docking: SNAREs and associates. Annu Rev Cell Dev Biol 1996;12:441-61.

24. Ullrich O, Stenmark H, Alexandrov K, et al. Rab GDP dissociation inhibitor as a general regulator for the membrane association of rab proteins. J Biol Chem 1993;268:18143-50

25. Ullrich O, Horiuchi H, Bucci C, Zerial M. Membrane association of Rab5 mediated by GDP-dissociation inhibitor and accompanied by GDP/GTP exchange. Nature 1994;368:157-60.

26. Valencia A, Chardin P, Wittinghofer A, Sander A. The ras protein family: evolutionary tree and role of conserved amino acids. Biochemistry 1991;30:4637-48.

27. Pai EF, Kabsch W, Krengel U, Holmes KC, John J, Wittinghofer A. Structure of the guanine-nucleotide-binding domain of the Ha-ras oncogene product p21 in the triphosphate conformation. Nature 1989;341:209-14

28. Wittinghofer A, Nassar N. How Ras-related proteins talk to their effectors. Trends Biochem Sci 1996;21:488-91.

29. Brennwald P, Novick P. Interactions of three domains distinguishing the Ras-related GTP-binding proteins Ypt1 and Sec4. Nature 1993;362:560-3.

30. Dunn B, Stearns T, Botstein D. Specificity domains distinguish the Ras-related GTPases Ypt1 and Sec 4. Nature 1993;362:563-5.

31. Stenmark H, Valencia A, Martinez O, Ullrich O, Goud B, Zerial M. Distinct structural elements of rab5 define its functional specificity. EMBO J 1994;13:575-83.

32. Beranger F, Paterson H, Powers S, de Gunzburg J, Hancock JF. The effector domain of Rab6, plus a highly hydrophobic C terminus, is required for Golgi apparatus localization. Mol Cell Biol 1994;14:744-58.

33. Feng Y, Press B, Wandinger Ness A. Rab7: an important regulator of late endocytic membrane traffic. J Cell Biol 1995;131:1435-52.

34. Deretic D, Papermaster DS. The role of small G-proteins in the transport of newly synthesized rhodopsin. In: Osborne NN, Chader GJ, editors. Progress in retinal and eye research, vol 14. New York: Pergamon Press, 1995:249-65. 
35. Martinez O, Antony C, Pehau Arnaudet G, Berger EG, Salamero J, Goud B. GTP-bound forms of rab6 induce the redistribution of Golgi proteins into the endoplasmic reticulum. Proc Natl Acad Sci USA 1997;94:1828-33.

36. Berson EL, Rosner B, Sandberg MA, Weigel DiFranco C, Dryja TP. Ocular findings in patients with autosomal dominant retinitis pigmentosa and rhodopsin, proline-347leucine. Am J Ophthalmol 1991;111:614-23.

37. Sandberg MA, Weigel DiFranco C, Dryja TP, Berson EL. Clinical expression correlates with location of rhodopsin mutation in dominant retinitis pigmentosa. Invest Ophthalmol Vis Sci 1995;36:1934-42.
38. Macke JP, Hennessey JC, Nathans J. Rhodopsin mutation proline347-to-alanine in a family with autosomal dominant retinitis pigmentosa indicates an important role for proline at position 347. Hum Mol Genet 1995;4:775-6.

39. Li T, Snyder WK, Olsson JE, Dryja TP. Transgenic mice carrying the dominant rhodopsin mutation P347S: evidence for defective vectorial transport of rhodopsin to the outer segments. Proc Natl Acad Sci USA 1996;93:14176-81.

40. Sung $\mathrm{CH}$, Makino $\mathrm{C}$, Baylor D, Nathans J. A rhodopsin gene mutation responsible for autosomal dominant retinitis pigmentosa results in a protein that is defective in localization to the photoreceptor outer segment. J Neurosci 1994;14:5818-33. 